DESIGN E INTERAÇÃo SOCIAL
Processos de Inovação Social

DESIGN E INTERAÇÃo SOCIA
Processos de Inovação Social 


\section{SOBRE OS AUTORES}

Amilton José Vieira de Arruda | arruda.amilton@gmail.com

Lattes: http://lattes.cnpq.br/9138096051015150

Possui graduação em Desenho Industrial pela UFPE (1982), mestrado em Design e Biônica pelo Centro Ricerche do Istituto Europeo de Design de Milão (1992) e doutorado e PhD em Desenho Industrial pela universidade Politecnico di Milano (2002). Foi consultor internacional do Istituto Europeo de Design de Milão na implantação de cursos de pós-graduação lato sensu nas faculdades Ávila (Goiânia) e FBV (Recife) e no Instituto de Educação Superior de Brasilia (DF). Desde 1985, é professor do curso de Design da UFPE. Docente do Programa de pós-graduação em Design da UFPE. Coordena o grupo de pesquisa Biodesign e Artefatos Industriais. Tem experiência na área de desenho industrial, com ênfase em design e biônica, atuando principalmente nos seguintes temas: desenvolvimento de produtos, design gráfico e editorial e design estratégico. Organiza, junto à editora Blucher, a série [designCONTEXTO].

Antônio Roberto Miranda de Oliveira | antonio.roberto83@gmail.com

Lattes: http://lattes.cnpq.br/7029604724644621

É bacharel em Design pela UFPE (2006-2010) e mestrando em Design no programa PPGD da UFPE (2016), tendo como linha de pesquisa design, tecnologia e cultura. Trabalha nas áreas de gestão do design, design estratégico, design thinking e design de negócios - gestão guiada pelo design (design management). Trabalhou como designer gráfico na Educandus — softwares educacionais (2007-2009); lecionou na faculdade AESO Barros Melo — Cinema e Animação (2009-2010). Tem experiência em agências publicitárias (2011-2013). É sócio-fundador na empresa Offstage Computação Gráfica até o presente momento. Principais atividades atualmente: ilustrador, designer de interiores e designer 3D. Seus focos são seu trabalho como designer 3D para virtualização arquitetônica 3D e o desenvolvimento de aplicativos mobile — tours virtuais em 3D, tecnologia de realidade aumentada (augmented reality), realidade virtual (virtual reality), tecnologia VR (projeto com uso de óculos VR para imersão virtual em ambiente 3D).

Ismael Gaião da Costa Filho I gaiaofilho@gmail.com

Lattes: http://lattes.cnpq.br/0927614774169610

É UX designer e pesquisador. Formado em Design (UFPE, 2014), atualmente é mestrando do mesmo curso no programa PPGD da UFPE. Atua como projetista UX na criação de aplicativos mobiles e softwares para uso de tecnologia e inovação, na UFPE e em empresas de tecnologia e educação. É tutor e professor adjunto no mestrado profissional em Engenharia de Software e no mestrado profissional em Design na faculdade C.E.S.A.R. Tem como base de trabalho pesquisas publicadas e apresentações em congressos internacionais sobre o estudo e o desenvolvimento de metodologias de Design aplicadas a projetos e criação de artefatos, com ênfase na inovação de projeto, na experiência do usuário e no estímulo do uso da criatividade.

Paulo Roberto Silva | pauloroberto.silva57@gmail.com

Lattes: http://lattes.cnpq.br/0756156215157410

Possui graduação em Desenho Industrial pela UFPE (1984), é especialista em Gestão da Qualidade e Produtividade (1995) e Engenharia de Produção (UFPE, 1996) e tem mestrado em Design, também pela UFPE (2006). Atualmente, é professor adjunto da mesma faculdade. Tem experiência profissional em gerência de produção de empresas, implantação de círculos de qualidade e ferramenta japonesa de 5s, consultoria em assistência tecnológica para o Sebrae e o Itep, sendo notadamente do setor moveleiro. É vice-coordenador do laboratório Biodesign da UFPE. Leciona as disciplinas Projeto do Produto, Materiais e Processos de Fabricação, Gestão e Empreendedorismo. Suas áreas de interesse são projeto do produto, design e sustentabilidade, inovação tecnológica, empreendedorismo, qualidade e produtividade nas organizações. Desde maio de 2014, é membro do comitê de ética da UFPE. É também membro titular do Centro de Artes e Comunicação. 


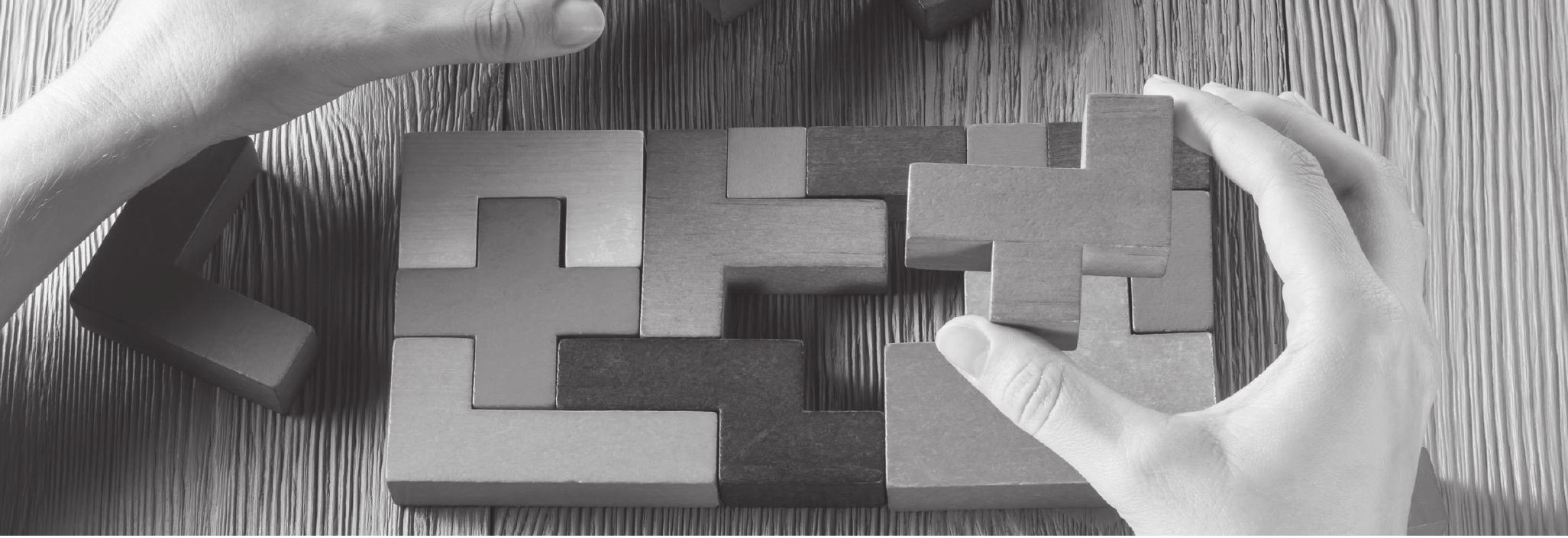

\title{
Design e os processos de inovação social como agentes transformadores em comunidades criativas
}

\author{
Diseño y los procesos de innovación social como \\ agentes de cambio en las comunidades creativas
}

Amilton José Vieira de Arruda, Antônio Roberto Miranda de Oliveira, Ismael Gaião da Costa Filho, Paulo Roberto Silva

\section{Resumo}

As comunidades criativas são iniciativas locais que empregam os recursos disponíveis no território com o intuito de resolver os problemas da vida cotidiana, promovendo métodos criativos de interação social de forma sustentável. É por meio desses grupos de pessoas que acontece a mobilização local em torno de atividades produtivas que possibilitam a inovação social, trazendo melhorias em niveis econômico, social, cultural e ambiental. 0 design pode colaborar com as comunidades criativas quando se transforma em agente de mudança, contribuindo para a viabilização de um programa de desenvolvimento local, comprometido com a valorização do território, da identidade e da sustentabilidade.

Palavras-chave: Comunidades Criativas; Inovação Social; Design Solidário.

\section{Resumen}

Las "Comunidades creativas" son iniciativas locales que emplean los recursos disponibles en el territorio con el fin de resolver los problemas de la vida cotidiana, la promoción de métodos creativos de interacción social de una manera sostenible. Es a través de estos grupos de personas que pasan a la movilización local en torno a las actividades productivas que permitan mejoras introducir la innovación social en los niveles económicos, sociales, culturales y ambientales. El diseño puede colaborar con las "Comunidades creativas", cuando se convierte en un agente de cambio, lo que contribuye a la viabilidad de un programa de desarrollo local, comprometida con el desarrollo y la planificación, la identidad y la sostenibilidad.

Palabras clave: Comunidades creativas; La innovación social; Diseño Solidario. 


\section{INTRODUÇÃO}

A vida da maioria das pessoas não é mais imaginável sem o design, estando presente na casa, no trabalho, na educação, na saúde, no esporte, no transporte de pessoas e bens, no ambiente público (BÜRDEK, 2006). Hoje se acredita que o design pode transformar o ambiente no qual é inserido, não mais se ligando somente à estética ou à funcionalidade de produtos, mas sim às variadas relações das condições humanas. Cada vez mais, ele tem-se mostrado como ferramenta estratégica de inovação para o desenvolvimento de produtos e serviços (MORAES, 2010).

Na busca pelo significado do design, o Conselho Internacional das Organizações de Design Industrial (ICSID, na sigla do nome em inglês) afirma que design é uma atividade criativa com o propósito de estabelecer as qualidades multifacetadas de objetos, processos, serviços e seus sistemas, compreendendo todo seu ciclo de vida. Para que o trabalho do designer seja mais efetivo e proveitoso, nessas iniciativas sociais é necessária uma abordagem sistêmica, demonstrando que essas formas de organização criativa se encontram cada vez mais emergentes, dentro de uma demanda social que busca um modelo de vida mais sustentável.

Uma excelente contribuição nesse campo surge com Margolin (2004), que colabora para o desenvolvimento da definição de design social. Ele escreve em seu livro A política do artificial a seguinte definição: "[...] designer e a sua capacidade de imaginar e dar forma em produtos materiais e imateriais que podem resolver os problemas humanos em larga escala e contribuir para o bem-estar social" (MARGOLIN, 2004).

Influenciando diretamente nessa definição, outros estudiosos, como Meroni (2007) e Manzini (2008), realizam suas contribuições nesse campo e acrescentam que a inovação social floresce contextualizada naquilo que eles classificaram como "comunidades criativas".

Meroni (2007) cunhou a expressão "comunidades criativas" e a define como um grupo de pessoas que, de forma colaborativa, inventam, aprimoram e gerenciam soluções inovadoras para novos modos de vida. Na tentativa de um estilo de vida sustentável, as comunidades criativas são iniciativas locais que fazem bom uso das fontes territoriais que promovem uma nova forma de interação social, com o intuito de resolver os problemas da vida cotidiana contemporânea. 
As comunidades criativas realizam ações no intuito de modificar os modelos de pensar e fazer, atuando com novas propostas e melhorias (MANZINI, 2008). É por meio delas que acontecem as mobilizações locais de indivíduos em torno de atividades produtivas que possibilitam a inovação social, trazendo melhorias nos âmbitos econômico, social, ambiental e cultural. Assim, comunidades criativas se configuram como exemplo de inovação social, conforme define Manzini (2008):

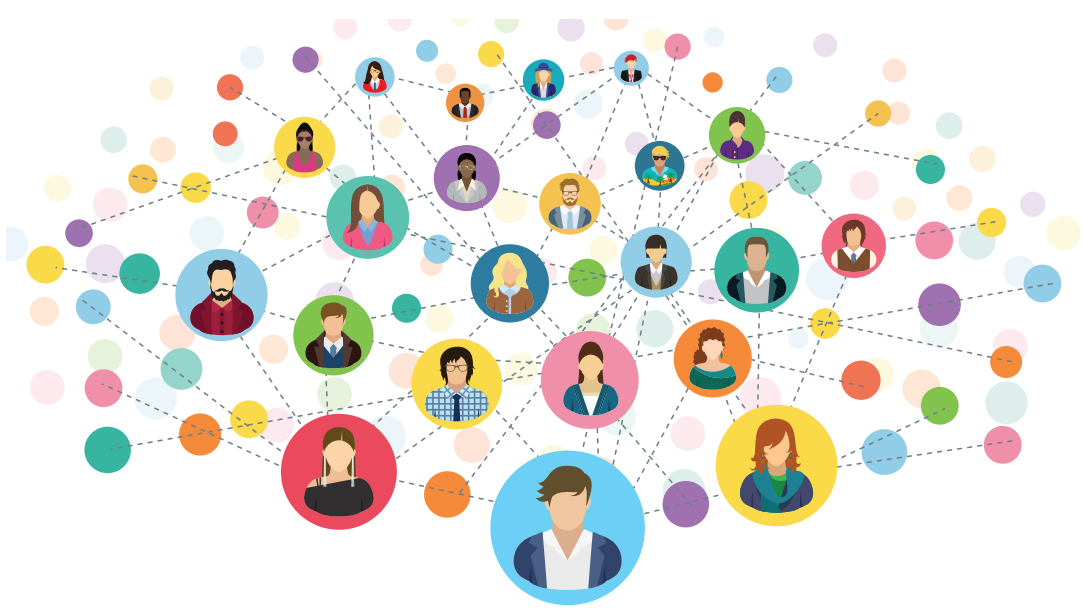

A partir desses conceitos, uma empresa instalada no agreste pernambucano trabalha permanentemente no intuito de integrar e beneficiar os indivíduos em seu território por meio de experiências, trocas e dinâmicas culturais, entendendo a criatividade e o design como elementos catalisadores do processo de desenvolvimento sustentável dessas comunidades criativas. Os resultados dessa experiência serão evidenciados ao final deste capítulo por meio de seus resultados, os quais apontam que o design, quando fomentador do processo de inovação social, torna-se um instrumento capaz de auxiliar no desenvolvimento local. A partir dessa experiência espera-se que os designers possam contribuir cada vez mais com as transformações de outras comunidades criativas pelo mundo.

\section{ASPECTOS DO DESIGN E INOVAÇÃO SOCIAL}

A inovação social pode ser definida como processo de design que visa contribuir para a melhoria social, a experiência e o bem-estar humanos a partir dos meios disponíveis, facilitando a execução local.
As "Comunidades Criativas" são

fortemente enraizadas em uma região $e$ isso faz com que esses grupos possam obter uma utilização e/ou reutilização das fontes locais disponiveis. Os empreendimentos sociais, assim como as "Comunidades Criativas", por serem organizações sociais complexas, não podem ser planejadas de maneira tradicional. (MANZINI, 2008, p. 68) 


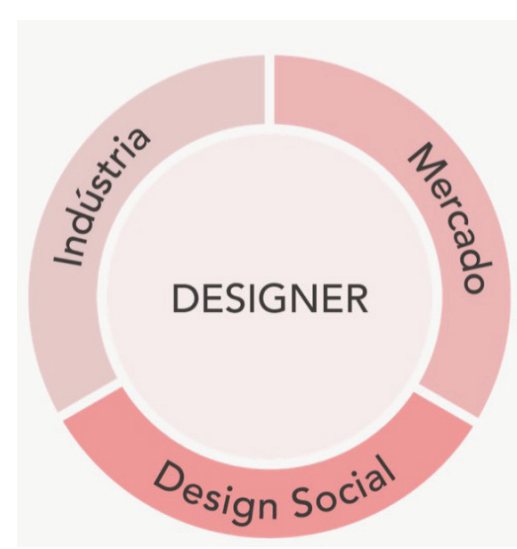

Contexto de localização do design no meio industrial, mercadológico e social. Fonte: Adaptada de Arruda (2015).
Um dos grandes pensadores sobre o tema foi Victor Papanek, que representava a ideia de que designers e profissionais de criação têm responsabilidade pelo que criam e são capazes de provocar mudanças reais no mundo, por meio do bom design. Papanek (1971) escreve que a responsabilidade dos designers pode contribuir para uma criação mais versátil socialmente, abordando questões importantes, como a ecologia.

Papanek (1971) comenta sobre o ato de projetar para as necessidades das pessoas, em vez de incluir as suas necessidades. 0 responsável pelo projeto inclui muitas direções e uma delas é aquela que volta projetos para lugares com mais necessidades e pouco desenvolvimento tecnológico. Designers têm responsabilidade sobre as escolhas que fazem em processos de design.

Já o designer social pensa em um mundo que une desenvolvimento humano e capital social, com novos produtos e processos que são rentáveis econômica e socialmente. A rentabilidade e a propriedade dos processos são os pilares de sustentabilidade que servem de base para o bem-estar humano.

Segundo nossas pesquisas, o design social faz parte de uma tríade composta pela indústria, mercado e segmento social (design social). Nela é compreendido que o designer, o projetista, tem ampla liberdade de buscar setores e segmentos para orientar o seu trabalho e que de cada um pode se extrair novos fatores e conhecimentos.

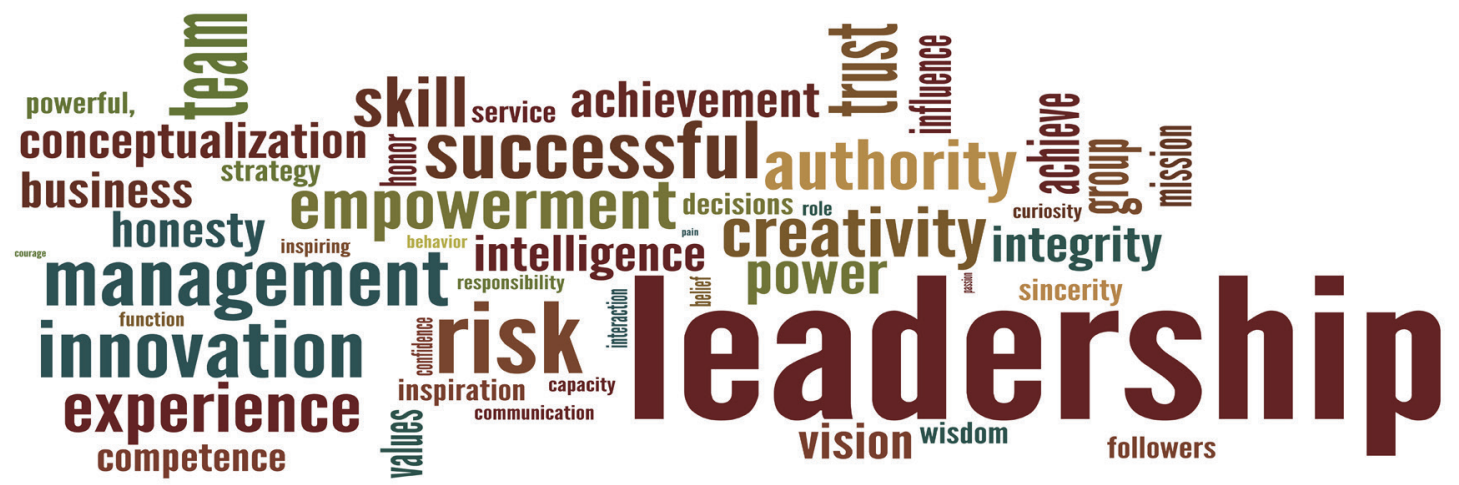

Por meio do conhecimento resultante das relações coletivas sociais ou de grupos, ainda de acordo com a ideia de rentabilidade, devem-se construir soluções que sirvam na projeção de produtos ou serviços que auxiliem as pessoas e as comunidades. Nesse aspecto, o designer atua como um 
agente para guiar a capacidade de o coletivo florescer, desenvolvendo as soluções habilitantes com uma finalidade geral para todos do grupo.

\section{DESIGN, DESENVOLVIMENTO SUSTENTÁVEL E INOVAÇÃO}

Diante de uma perspectiva de não tratar o design de forma isolada, é possivel perceber sua real essência e um evidente salto na participação de questões econômicas, culturais, ambientais e sociais. A partir desse enfoque, nota-se um caminho tênue e imprescindivel ao design, na busca de relações humanas no meio em que vive, promovendo melhorias na qualidade de vida, novos métodos e abordagens mais criativas, trazendo um forte impacto positivo na sociedade.

Devido a essas mudanças, surgem iniciativas com intuito de resolver os problemas do cotidiano, promovendo métodos criativos de interação social de forma sustentável que buscam atender ao bem-estar social. Nesse aspecto de solucionar problemas, de criar sistemas de produção que vão ao encontro das demandas da sociedade, de gerar novas oportunidades a partir da criatividade que possuem, insere-se o papel relevante do design, que para Löbach (2001) é uma ideia, um projeto ou um plano para a solução de um problema determinado.

Para Martins (2004 apud MOZOTA, 2002), definir as competências do design é discorrer sobre a natureza de uma profissão em seus diferentes campos de intervenção e nos métodos utilizados em seus projetos. Emprega-se, atualmente, o termo design para descrever essa profissão em sua totalidade e designer para todo profissional que a pratique. Nessa perspectiva, segundo Manzini (2008):

Essa transição fundamentada na sustentabilidade, na proteção ao meio ambiente, será cada vez mais difundida na sociedade, por meio de diversificadas formas de criatividades, conhecimentos, capacidades organizacionais, e os designers deverão ter um conhecimento mais amplo e menos rígido a mudanças.

Segundo Cipolla (2012), para atender às necessidades de mudanças da sociedade, surgem iniciativas locais com o intuito de resolver os
Os designers podem ser parte da solução, justamente por serem os atores sociais que, mais do que quaisquer outros, lidam com as interações cotidianas dos seres humanos com seus artefatos. São precisamente tais interações, junto com as expectativas de bem-estar a elas associadas, que devem necessariamente mudar durante a transição rumo à sustentabilidade. [...] é oferecer novas soluções a problemas, sejam velhos ou novos, e propor seus cenários como tema em processos de discussão social, colaborando na construção de visões compartilhadas sobre futuros possiveis e sustentáveis. (MANZINI, 2008, p.16) 
O conceito de desenvolvimento sustentável prevê a melhora da qualidade de vida da população mundial sem utilizar recursos que vão além da capacidade do planeta em regenerar esses recursos. Dessa maneira os mesmos estariam disponíveis para futuras gerações, através de diferentes ações que integram três áreas fundamentais: crescimento econômico e equidade, conservação dos recursos naturais e do meio ambiente e desenvolvimento social. (BRUNDTLAND, 1991 apud (IPOLLA, 2012)

\section{[...], iniciativas podem ser consideradas} exemplos de "Comunidades Criativas", ou seja, grupos de pessoas que realizam ações no intuito de resolver os problemas do dia-a-dia motivadas pelas suas necessidades especificas. É através delas que acontece a mobilização local de indivíduos em torno de atividades produtivas que possibilitam a inovação social, trazendo melhorias em niveis econômico, ambiental, social e cultural. (CIPOLLA, 2012, p. 38) problemas do cotidiano. 0 desenvolvimento sustentável é o motor que procura satisfazer as necessidades da geração atual, sem comprometer a capacidade das gerações futuras. Diz Brundtland (1991 apud CIPOLLA, 2012):

Como afirma Cipolla (2012),

Esses casos expressam uma preocupação com desenvolvimento sustentável e empreendedorismo social, carregando a inovação como um componente essencial em sua definição, ou seja: para resolver problemas sociais é necessário desenvolver iniciativas com potencial de inovação social transformadora de uma realidade local, nacional ou mundial (MADRUGA, 2009). As grandes transformações sociais que podem acontecer a partir da inovação são aquelas que se apoiam em cinco pilares: econômico, social, cultural, político e ambiental.

A expressão desenvolvimento sustentável foi introduzida pela primeira vez em um debate internacional no documento da Comissão Mundial para o Ambiente e o Desenvolvimento chamado "Nosso futuro comum" (Our Common Future), até ser usada como tema principal, em 1992, no Rio de Janeiro, na Conferência das Nações Unidas sobre Ambiente e Desenvolvimento (MANZINI, 2008).

Essa também é peça fundamental no planejamento público e encontra respaldo na Administração Pública. A Lei n. 8.666/93 regula o processo de licitação pública e, em seu artigo $3^{\circ}$, destina-se a garantir a observância da promoção do desenvolvimento nacional sustentável. O Decreto n. 7.746/12 regulamenta esse artigo e estabelece critérios, práticas e diretrizes gerais para a promoção do desenvolvimento nacional sustentável por meio das contratações realizadas pela administração pública. Em seu artigo $4^{\circ}$, o Decreto aponta diretrizes de sustentabilidade em um rol não exaustivo:

I - menor impacto sobre recursos naturais como flora, fauna, ar, solo e água;

II - preferência para materiais, tecnologias e matérias-primas de origem local;

III - maior eficiência na utilização de recursos naturais como água e energia;

IV - maior geração de empregos, preferencialmente com mão de obra local; 
V - maior vida útil e menor custo de manutenção do bem e da obra;

VI - uso de inovações que reduzam a pressão sobre recursos naturais; $e$

VII - origem ambientalmente regular dos recursos naturais utilizados nos bens, serviços e obras.

Nos últimos anos, o conceito de desenvolvimento sustentável tem sido inserido no cenário político internacional como um termo que se refere às condições sistêmicas de desenvolvimento produtivo, social, com âmbito ambiental, ou seja, levando em conta a capacidade do planeta de absorver os impactos ambientais gerados pelo homem e se regenerar (VEZZOLI, 2010).

No entanto, dentro dessa realidade, iniciativas locais serão mais capazes de romper os padrões consolidados, com novos comportamentos e modos de pensar. Segundo Manzini (2008), a inovação social encontrase dentro dessas iniciativas locais, em que a experiência nos indica que períodos particularmente intensos de inovação social tendem a ocorrer quando novas tecnologias penetram nas sociedades ou quando problemas particularmente urgentes ou difusos devem ser enfrentados.

Segundo Manzini (2008):

Langenbach (2008) cita casos que foram inovadores socialmente e hoje viraram um padrão estabelecido na busca por suprir as necessidades ainda não atendidas, de modo a melhorar a vida das pessoas, como: grupos de autoajuda, alcoólicos anônimos, narcóticos anônimos, mutirões para construção de casas populares, enfermarias comunitárias e até seguranças privadas nos bairros. Nesse aspecto, as inovações sociais surgem às margens da sociedade e buscam uma nova tendência ou solução social para o futuro.

A essas iniciativas dá-se o nome de comunidades criativas - grupos de pessoas que realizam ações no intuito de resolver os problemas do dia a dia, motivadas pelas suas necessidades específicas (CIPOLLA, 2012).

Nos últimos anos, nota-se um aumento de empresas que investem em design como se investissem em inovação. 0 modelo tradicional baseado no investimento em novas tecnologias está deixando de ser considerado suficiente para a inovação. As empresas estão percebendo gradualmente que não basta ter uma tecnologia sem um projeto que a torne útil.
O termo inovação social refere-se a mudanças no modo como indivíduos ou comunidades agem para resolver seus problemas ou criar novas oportunidades. Tais inovações são guiadas mais por mudanças de comportamento do que por mudanças tecnológicas ou de mercado, geralmente emergindo através de processos organizacionais 'de baixo para cima' em vez de daqueles 'de cima para baixo'. (MANZINI, 2008, p. 61)

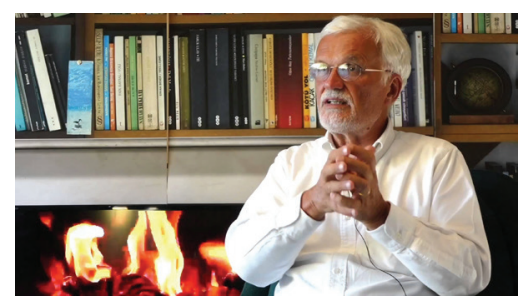

Prof. Ezio Manzini.

[...] a definição de inovação social, consequentemente, indica também o reconhecimento dos limites do modelo atual de produção e consumo, considerando não somente termos ambientais, mas também questões econômicas, sociais e institucionais. Apesar do fato de que inovações sociais podem ser não planejadas ou acontecer espontaneamente, se condições favoráveis forem criadas por meio do design, elas podem ser encorajadas, empoderadas, reforçadas, ampliadas e integradas com programas maiores para gerar mudanças sustentáveis. (CIPOLLA, 2012, p. 65-66) 
A palavra criar vem do sentido de dar origem, gerar ou formar algo. Logo, "criação" é a ação de criar. "criação é o próprio processo onde se provoca a existência de algo novo" (PLAZA; TAVARES, 1998). Segundo Ostrower (1987), criatividade é "poder dar uma forma a algo novo". Em qualquer que seja o campo da criatividade, trata-se, nesse "novo", de novas coerências que se estabelecem para a mente humana, fenômenos relacionados de modo novo e compreendidos em termos novos. $\mathrm{O}$ ato criador abrange, portanto, a capacidade de compreender; e esta, por sua vez, a de relacionar, ordenar, configurar, significar.

Gomes (2002), na área de projeto, compreende que a criatividade é "o conjunto de fatores e processos, atitudes e comportamentos que estão presentes no desenvolvimento do pensamento produtivo". Ainda afirma que "no desenho projetual, a criatividade se aplica à definição de forma, função e até informação em produtos". Plaza e Tavares (1998) também mostram que na geração de alternativas e na concepção de produtos, como é o caso dos jogos eletrônicos, a criatividade atua como o conjunto de processos que trabalham as informações e que, organizados e submetidos à análise combinatória, ajudam na resolução de problemas iniciais de tomada de decisão na concepção de jogos eletrônicos.

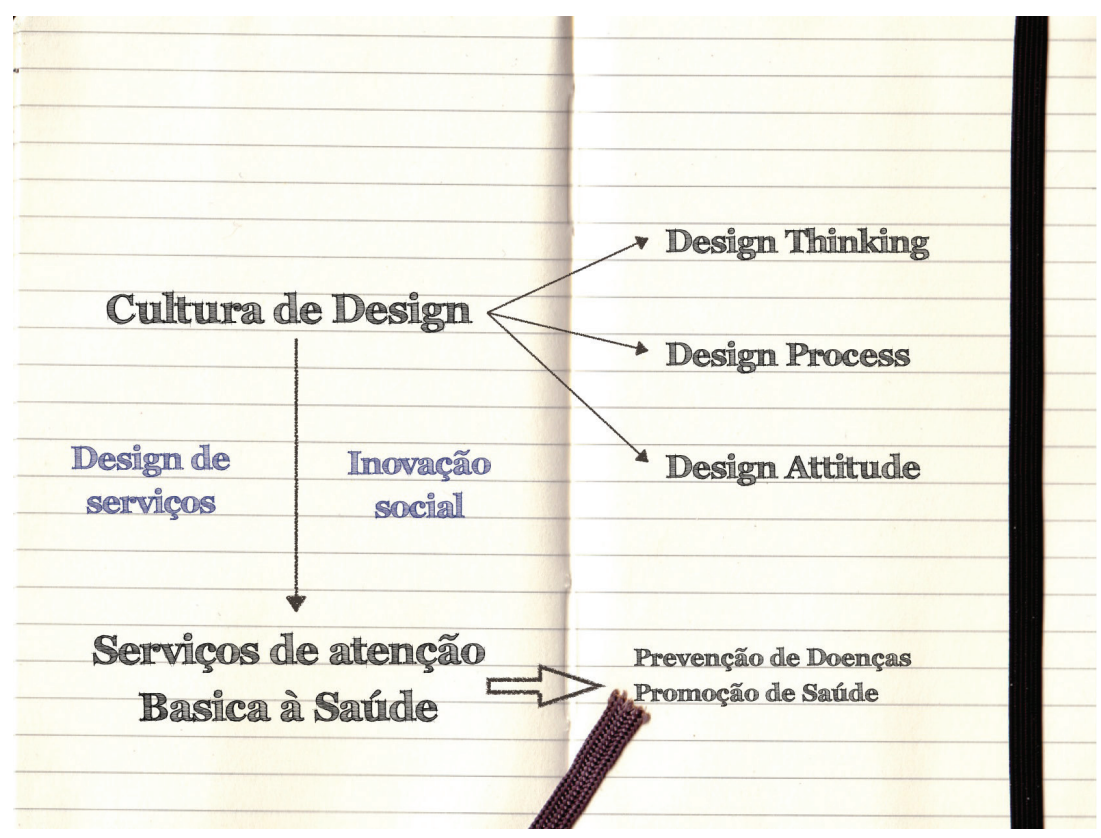


Joseph Schumpeter (1947) analisa a inovação do ponto de vista de seu criador, aquele que projeta o artefato, e da valorização do designer, nesse caso como um atuante direto no processo de projetar. "A inovação é o uso da criatividade por um inventor para criar ideias, denominadas invenções. Uma vez que essas invenções são implementadas, o inventor passa a se tornar um empreendedor e a invenção se torna inovação" (SCHUMPETER, 1947). Apesar de ser uma definição análoga, é interessante para apresentar um pensamento antigo, mas que já se preocupava com os conceitos de inovação e do profissional que poderia dar garantias para a execução desse tipo de processo metodológico.

"O design é o elo entre a criatividade e inovação" (CRUICKSHANK, 2010). Esse pensamento é tão interessante quanto discutível, porém se encaixa bastante na problemática apresentada nas pesquisas abordadas até hoje na ciência. É uma visão bem mais moderna e completa para colocar o design como um ponto essencial para a execução do projeto. Cruickshank desenvolveu seus estudos sobre essa temática classificando de forma aplicável onde se encaixa o design e sua atuação em busca desse desejo infinito de inovação para a produção. Essa abordagem não usual reforça a necessidade de conhecimento do designer sobre metodologias e, principalmente, a necessidade de as empresas/academias/grupos de estudo terem um designer atuando dentro do círculo para melhores ganhos futuros.

\section{APLICAÇÕES DA INOVAÇÃO QUE PERMITAM O DESENVOLVIMENTO SOCIAL}

O termo design social é também cada vez mais utilizado para descrever a concepção do mundo social. Essa definição implica uma percepção de uma realidade feita pelo homem, o que, consequentemente, só pode ser mudada pelo homem, e é mudada pelo homem o tempo todo. Nesse modo de exibição de design social é inevitável saber se as pessoas estão conscientes disso ou não. A realidade social é criada como um resultado da soma de todas as nossas ações individuais. Há uma discussão emergente do conceito de design social que engloba todas as outras definições do termo.
As necessidades básicas, de consumo e outras, podem originar um problema de design. A solução de problemas melhora a qualidade de vida. Eles podem ser especificados pelo designer e propostos à indústria, ou pode ser a indústria a propor ao designer a resolução de algum problema. Muito frequentemente, porém, a indústria tende a inventar falsas necessidades para poder produzir e vender novos produtos. Nesse caso, o designer não deve deixar-se envolver numa operado que se destina ao lucro exclusivo do industrial e ao prejuízo do consumidor. (MURANI, 1981) 
"Toda mudança tecnológica tem potencial para ser adorada e odiada" (PETROSKI, 1992). Os feedbacks, sejam eles feitos por outros profissionais ou usuários, podem ser completamente diferentes, proporcionalmente ao nivel de inovação que o artefato alcança. A tecnologia é o melhor exemplo disso, mostrando que é possivel averiguar toda a atenção que um novo produto Apple ou Google causa no mercado, tanto por pessoas fascinadas quanto pelas que se perguntam para que vai servir o artefato novidade do momento. No mercado de ações também é notável as alterações da aplicação e criação de um novo artefato no mercado de consumo. As alterações que os valores dessas empresas alcançam quando um novo produto é criado é impressionante.

Do ponto de vista individual, qualquer um pode se utilizar da inovação social para promover mudanças profundas e benéficas em que todos ganham, seja por meio de um negócio, organização filantrópica, governo ou outros movimentos da sociedade civil. No entanto, para entender o macrocontexto em que a inovação social está inserida e como acontecem as mudanças sistêmicas é preciso resgatar a perspectiva sociológica. Tradicionalmente, a sociedade civil está classificada em três grandes blocos, agrupando os principais atores sociais:

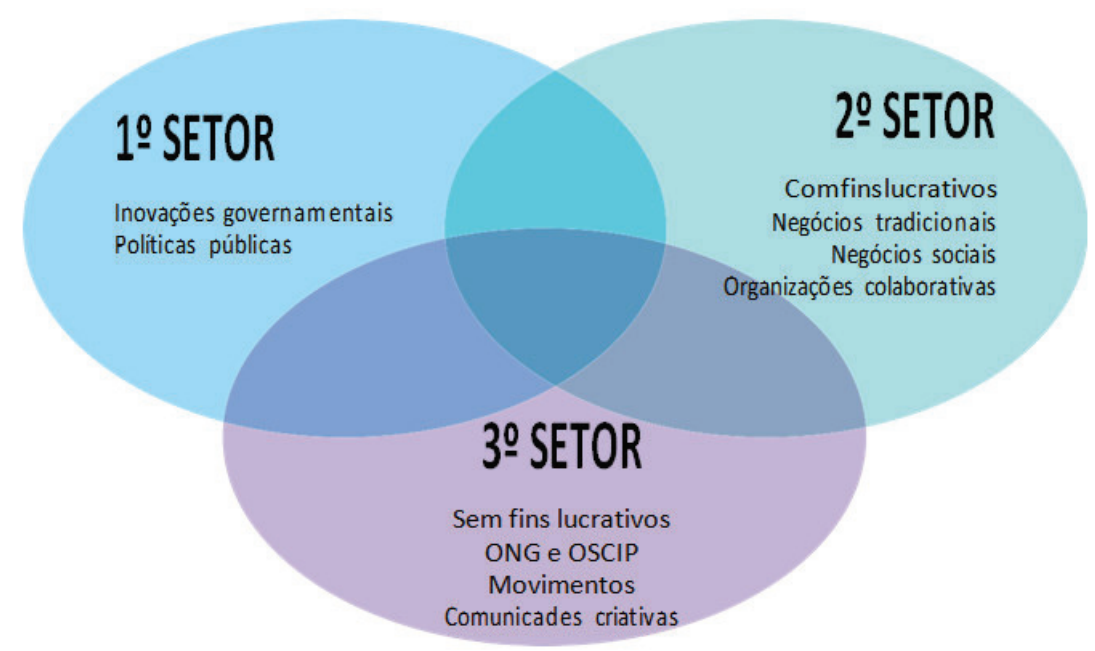



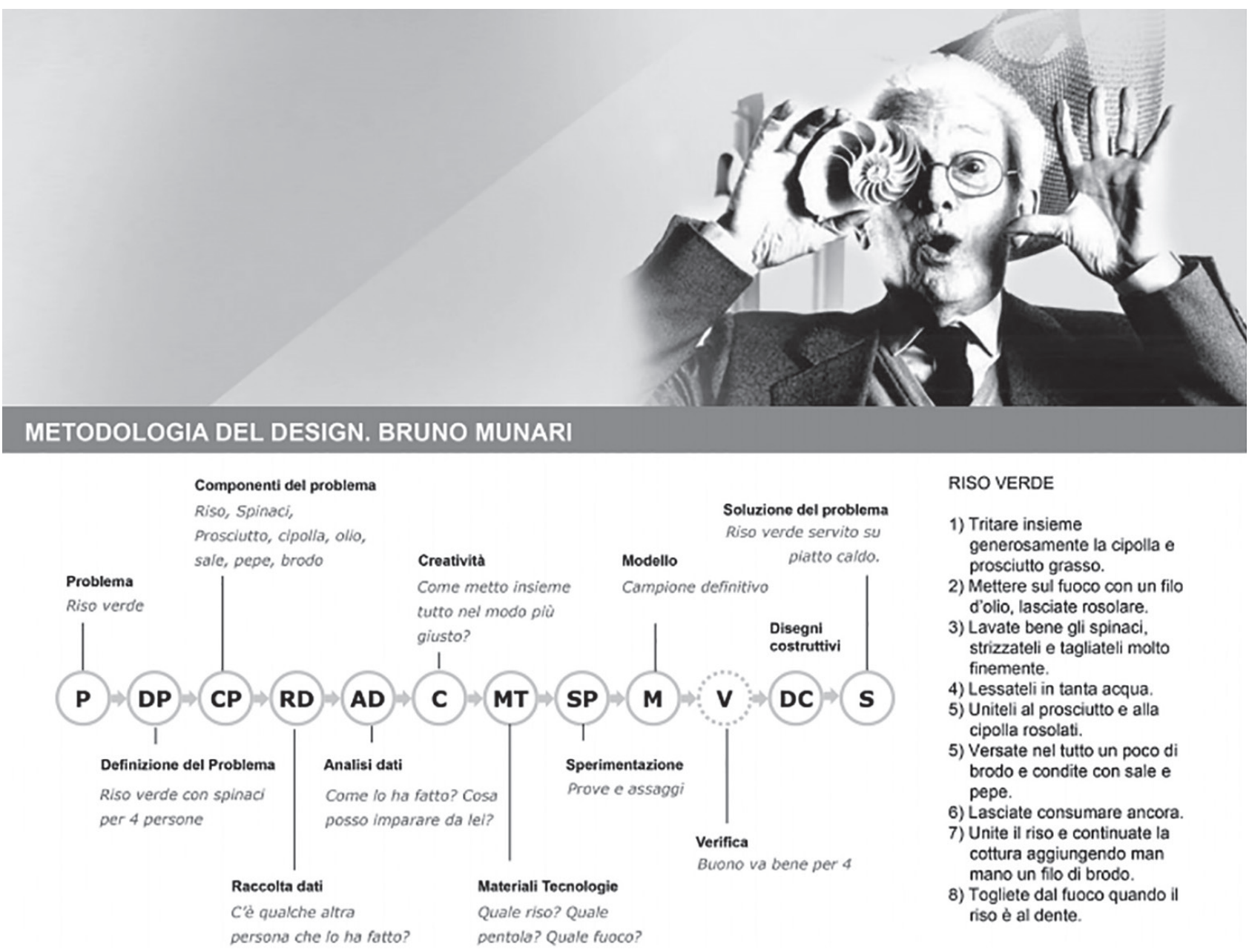

RISO VERDE

1) Tritare insieme generosamente la cipolla e prosciutto grasso.

2) Mettere sul fuoco con un filo d'olio, lasciate rosolare.

3) Lavate bene gli spinaci, strizzateli e tagliateli molto finemente.

4) Lessateli in tanta acqua.

5) Uniteli al prosciutto e alla cipolla rosolati.

5) Versate nel tutto un poco di brodo e condite con sale e pepe.

6) Lasciate consumare ancora.

7) Unite il riso e continuate la cottura aggiungendo man mano un filo di brodo.

8) Togliete dal fuoco quando il riso è al dente.

\section{UM CASO ENTRE TANTOS}

A Art Gravatá é um grupo de produção solidária de brinquedos educativos e materiais pedagógicos feitos em madeira composto por oito artesãos localizado em Gravatá (PE) que faz parte da Associação Círculo de Trabalhadores Cristãos de Gravatá (CTCG), fundada em maio de 1962, uma entidade civil com fins não econômicos que visa o desenvolvimento socioeconômico e cultural do homem por meio de uma economia popular e solidária. A Art Gravatá iniciou suas atividades em 1979 com a produção de artesanato decorativo e utilitário, brinquedos educativos, material pedagógico e mobiliário escolar. 


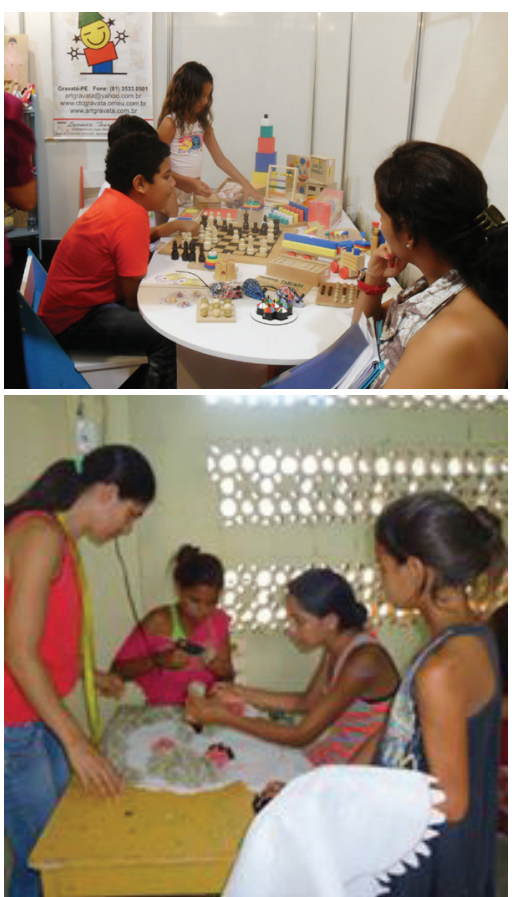

Atendimento à comunidade, em especial às crianças da comunidade, com cursos de capacitação. Fonte: http://ctcgravata. blogspot.com.br/2010/12/art-gravataparticipou-da-expoidea.html.:
De uma forma geral, a Art Gravatá segue os princípios do Comércio Justo: a criação de oportunidades, trabalho e renda; o relacionamento transparente entre os produtores e parceiros comerciais; o cultivo do respeito e da abertura para expressão de suas ideias e opiniões.

Segundo Mario Sergio, gerente da ONG, Art Gravatá é um projeto social de geração de trabalho e renda do Movimento Circulista (Círculo de Trabalhadores Cristãos de Gravatá), uma ONG que tem por finalidade a promoção integral do ser humano nos setores econômico, político, social, cultural, educacional e religioso.

O projeto iniciou as suas atividades em 1979 e atualmente é composto por dez produtores, os quais fabricam brinquedos educativos, brindes e artesanatos, todos sob encomenda. A matéria-prima utilizada é o MDF e a madeira pinus. Desde 1999, participa de debates sobre comércio justo e solidário por meio de fóruns e redes de economia solidária.

A uma comunidade criativa em sintonia com as definições já explicitadas, atuando com a cultura e produção local e matérias-primas sustentáveis, voltando-se para a economia solidária e o comércio justo.

Entende-se como economia solidária uma forma diferente de produzir, vender, comprar e trocar aquilo que é necessário para a sobrevivência. Comparando-a com a economia convencional, enquanto nesta existe a separação entre os proprietários do negócio e os empregados, na economia solidária os próprios trabalhadores também são proprietários. São eles quem tomam as decisões de como conduzir o negócio, dividir o trabalho e repartir os resultados.

Há milhares de iniciativas econômicas em que os trabalhadores estão organizados coletivamente: associações, cooperativas e grupos de produtores; cooperativas de coleta e reciclagem; empresas recuperadas assumidas pelos trabalhadores; redes de produção, comercialização e consumo; bancos comunitários; cooperativas de crédito, entre outras.

A economia solidária é uma alternativa inovadora na geração de trabalho e inclusão social, na forma de uma corrente do bem que integra quem produz, quem vende, quem troca e quem compra. Seus princípios são autogestão, democracia, solidariedade, cooperação, respeito à natureza, comércio justo e consumo solidário. 


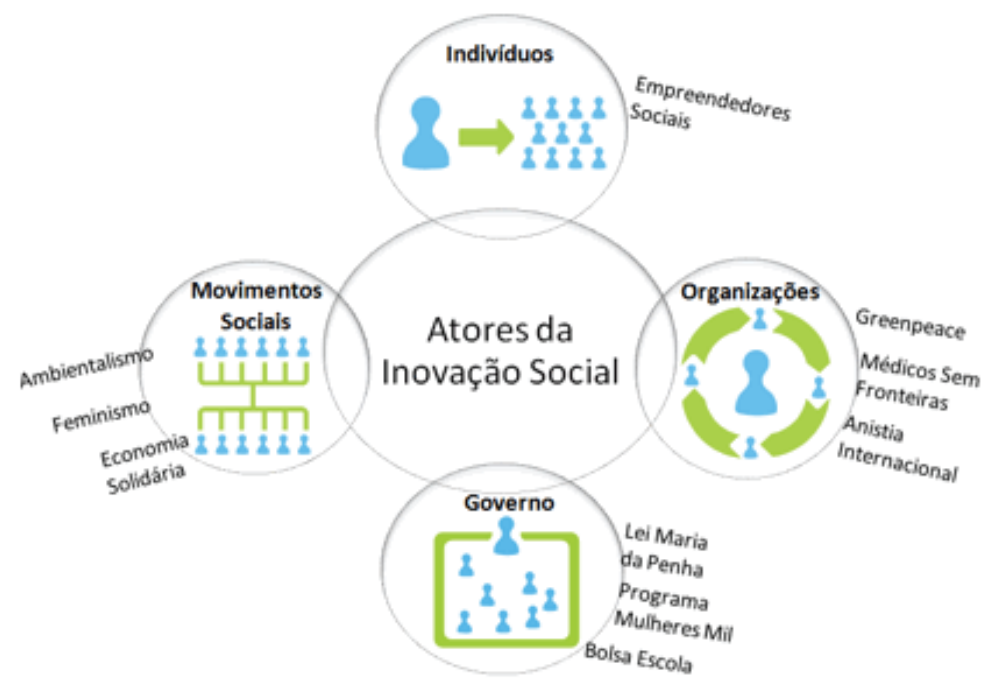

Alguns princípios muito importantes para a economia solidária. Fonte: http://trabalho. gov.br/trabalhador-economia-solidaria/o-que-e.

A Art Gravatá participa do Comércio Justo e Solidário, do Cirandas, do site da Economia Solidária, no qual comercializa seus produtos, e de redes sociais, como o Facebook.

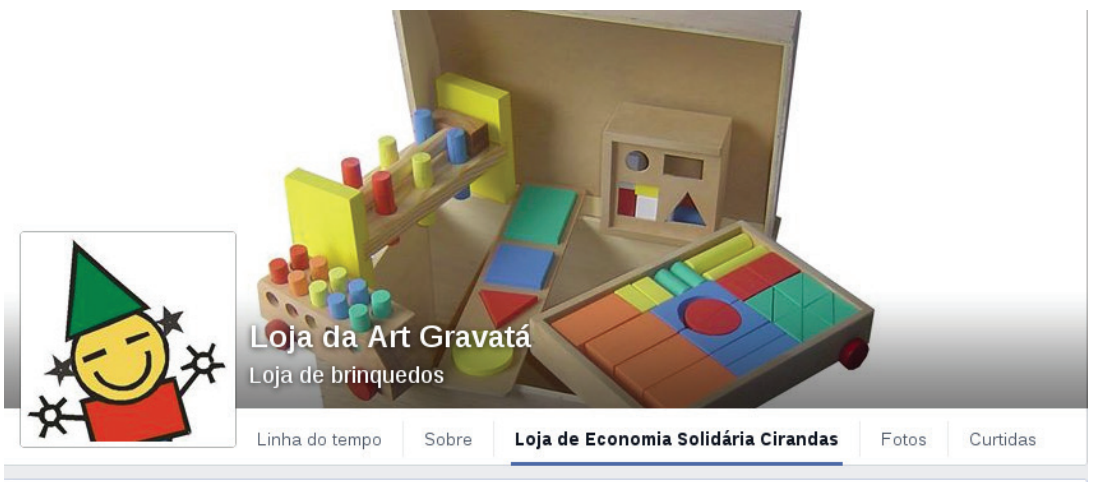

\section{\#t cirandas Loja de Economia Solidária}
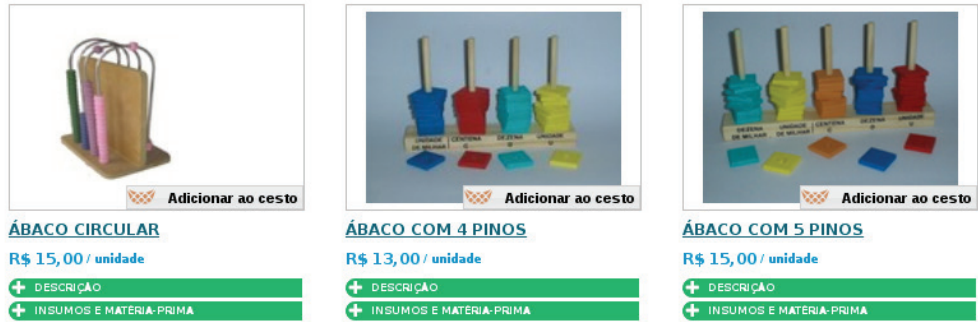

Site para comercialização dos produtos. Fonte: ola.coop.br/patriciaconceicao/blog. 


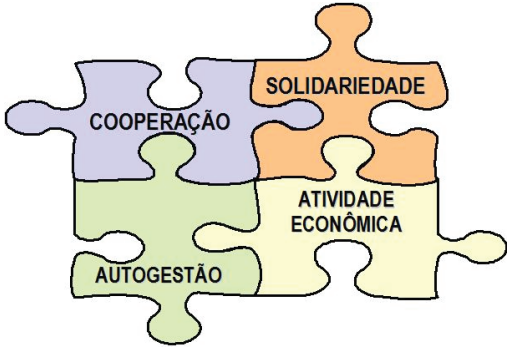

Pilares da economia solidária. Fonte: http:/leconomiasolidariasustentavel. blogspot.com.br/.
Alguns princípios adotados pela Art Gravatá baseados nos conceitos do programa de economia solidária são: cooperação: em vez de competir, todos devem trabalhar de forma colaborativa, buscando os interesses e objetivos em comum, a união dos esforços e capacidades, a propriedade coletiva e a partilha dos resultados; autogestão: as decisões nos empreendimentos são tomadas de forma coletiva, privilegiando as contribuições do grupo em vez de ficarem concentradas em um indivíduo. Todos devem ter voz e voto; ação econômica: sem abrir mão dos outros princípios, a economia solidária é formada por iniciativas com motivação econômica, como a produção, a comercialização, a prestação de serviços, as trocas, o crédito e o consumo; solidariedade: a preocupação com o outro está presente de várias formas na economia solidária, como na distribuição justa dos resultados alcançados, na preocupação com o bemestar de todos os envolvidos, nas relações com a comunidade, na atuação em movimentos sociais e populares, na busca de um meio ambiente saudável e de um desenvolvimento sustentável.

Entendendo todos esses fatores e buscando aplicar de forma direta cada elemento do um projeto social, de um projeto solitário, economicamente e ambientalmente sustentável, foi realizado um projeto de extensão dentro da UFPE, "Intervenção do design no processo produtivo e brinquedos educativo da Art Gravatá", coordenado pelo Prof. Paulo Roberto Silva, tendo como objetivos gerais e norteadores:

a. fortalecer a missão da empresa e ampliar a visibilidade de seus produtos, fortalecendo a visão de sua finalidade educativa;

b. analisar e propor alterações incrementais no sistema produtivo;

c. ampliar a linha de brinquedos educativos a partir de novas demandas de mercado;

d. desenvolver catálogos, site e mobiliário que melhorem a visibilidade dos brinquedos e favoreçam a interação das crianças com os produtos educativos em lojas e exposições;

e. ampliar a rede de relações com consumidores e ONG que possam favorecer as vendas por meio, inclusive, do comércio solidário.

A partir da dimensão econômica e produtiva, tratada anteriormente, na qual procuramos construir uma sustentabilidade econômica a partir do equilíbrio de forças produtivas e ecológicas, foi necessário desenvolver algumas ações de design para melhor atender esse segmento. 
Dentro dos conhecimento do design, adotamos princípios de sustentabilidade, de forma a contribuir para o melhor posicionamento da empresa no mercado, bem como melhorar a qualidade dos produtos e do processo produtivo como o todo. E para isso adotamos os conceitos de Manzini e Vezzoli (2005) quando, tratando do papel das empresas, afirmam que,

As propostas que veremos a seguir foram realizadas por um grupo de alunos do curso de Design da UFPE, somado a um projeto de extensão da mesma instituição, no qual se buscou, por meio de uma linha especifica de brinquedos educativos, atender as novas demandas de mercado e abrir novas redes de relacionamento e novos canais de relacionamento. Os alunos visitaram escolas, centros de reabilitação, institutos, universidades e realizaram entrevistas com professores, profissionais e alunos para que pudessem obter demanda e dados para o desenvolvimento de seus projetos.
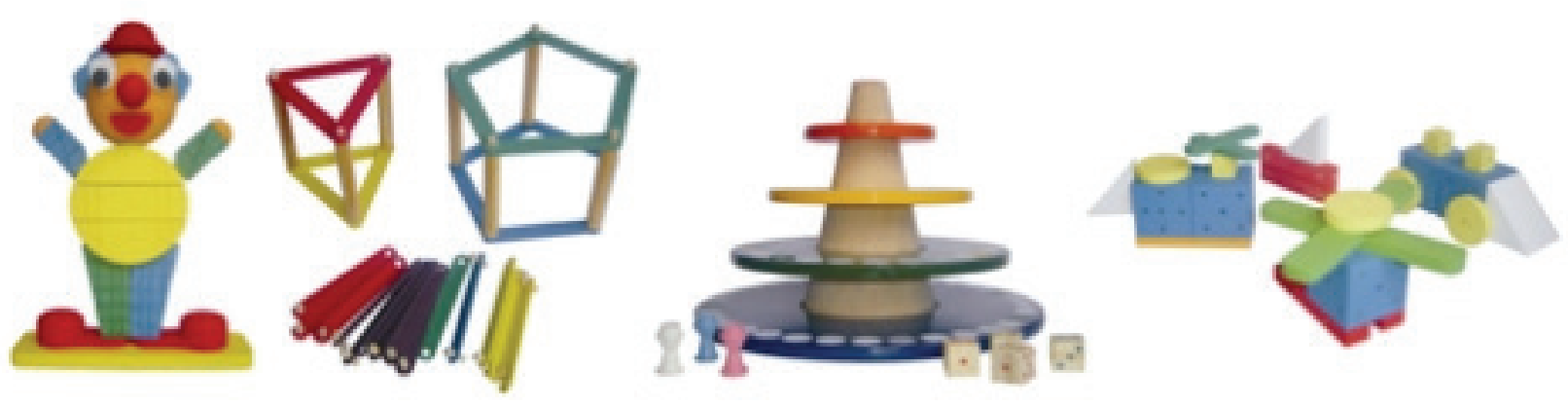

[...] para que as empresas possam agir verdadeiramente como agentes da sustentabilidade, usando da melhor maneira os recursos que dispõem, é necessário que as suas atividades sustentáveis sejam orientadas e traduzidas no caminho da competitividade. Neste caso especifico, a competitividade viria não apenas de uma visão puramente econômica e capitalista, mas da valorização do processo produtivo artesanal e da cultura local, da missão social da empresa e da valorização do produto produzido em concordância com os princípios de sustentabilidade social e ecológica. (MANZINI; VEZZOLI, 2005)

Fotos de protótipos de projetos desenvolvidos pelos alunos e bolsistas. Fonte: Paulo Silva, UFPE.

Durante todo o projeto, procuramos atender os pontos que considerávamos prioritários, concentrando esforços nos mais importantes:

1. Desenvolvimento do site da empresa e registro de seu domínio www.artgravata.com.br, já que ela só possuía um Photolog e não tinha ainda o domínio.

2. Redesign da marca da empresa, tornando-a mais moderna e infantil. 
3. Criação de uma nova linha de material gráfico, como folders, catálogos e cartões, já que os anteriores eram antigos.

4. Fluxo produtivo, racionalização de matéria-prima, segurança, redução de tempo, energia e consequentes custos produtivos, além da priorização de fornecedores locais e uso de matériasprimas de fontes renováveis.

5. Mobiliário para exposição e interação das crianças com os brinquedos educativos, contribuindo para uma melhor compressão da finalidade educativa dos brinquedos, ampliando a sua visibilidade, favorecendo as vendas e um consequente aumento nas encomendas de produtos da empresa.

\section{REFERÊNCIAS}

ALGUNS princípios são muito importantes para a economia solidária. Disponível em: <http:/l trabalho.gov.br/trabalhador-economia-solidaria/oque-e>. Acesso em: 1 out. 2016.

ARRUDA, A. J. V. (Org.). Design e complexidade. Sustentabilidade no século XXI: história e possibilidades de avanço através do PPS. Vários autores. Recife: EdUFPE, 2015.

BONSIEPE, G. Design, cultura e sociedade. São Paulo: Blucher, 2011.

BRASIL. Lei n. 8.666, de 21 de junho de 1993. Regulamenta o art. 37, inciso XXI, da Constituição Federal, institui normas para licitações e contratos da Administração Pública e dá outras providências. Brasília: DOU, 1993.

Decreto n. 7.746, de 5 de junho de 2012. Regulamenta o art. 30 da Lei no 8.666, de 21 de junho de 1993, para estabelecer critérios, práticas e diretrizes para a promoção do desenvolvimento nacional sustentável nas contratações realizadas pela administração pública federal, e institui a Comissão Interministerial de Sustentabilidade na Administração Pública CISAP. Brasilia: DOU, 2012.

BROWN, T. Design Thing for Social Innovation. Stanford Social Innovation Review, 2010

BRUndtLAND, G. H. Nosso Futuro Comum. Comissão Mundial sobre o Meio Ambiente e Desenvolvimento. Fundação Getúlio Vargas: Rio de Janeiro, 1991. Disponível em: <http:// pt.scribd.com/doc/12906958/Relatorio-Brundtland-Nosso-Futuro-Comum-Em-Portugues> Acesso em: 15 abr. 2017.

BÜRDEK, B. E. Design: história, teoria e prática do design de produtos. Tradução de Freddy Van Camp. São Paulo: Blucher, 2006.

CIPOLLA, C. Design, inovação social e sustentabilidade. In: MORAES, D. et al. (Org.). Coleção Cadernos de Estudos Avançados em Design: Inovação. Barbacena: EdUEMG, 2012.

CRUICSHANK, L. The innovation dimension. Massachusetts: Design Issues, Massachusetts Institute of Technology, v. 26, n. 2, 2010.

GIDDENS, A. Sociology. 4. ed. Cambridge: Polity, 2001.

LANGENBACH, M. Além do apenas funcional. Inovação social e design de serviços na realidade brasileira. 2008. 123 f. Dissertação (Mestrado em Engenharia de Produção) - Universidade Federal do Rio de Janeiro, Rio de Janeiro. 2008 
LÖBACH, B. Design industrial: bases para a configuração dos produtos industriais. São Paulo: Blucher, 2001.

MADRUGA, L. Comportamento coletivo e interações sociais no comitê de gerenciamento da bacia hidrográfica do rio Santa Maria: aprendizagem social e emergência do empreendedorismo socioambiental. 2009. 359 f. Tese (Doutorado) - Universidade Federal do Rio Grande do Sul, Centro de Estudos e Pesquisas em Agronegócios, Programa de Pós-Graduação em Agronegócios, Rio Grande do Sul. 2009.

MANZINI, E. Design para a inovação social e sustentabilidade: comunidades criativas, organizações colaborativas e novas redes projetuais. Tradução de Carla Cipolla. Rio de Janeiro: E-papers, 2008.

MANZINI, E.; VEZZOLI, C. O desenvolvimento de produtos sustentáveis. Tradução de Astrid de Carvalho. São Paulo: EdUSP, 2005.

MARGOLIN, V.; MARGOLIN, S. Um "modelo social" de design: questões de prática e pesquisa. Revista Design em Foco, 2004.

MARTINS, R. F. F. A gestão de design como estratégia organizacional: um modelo de integração do design em organizações. Tese (Doutorado em Engenharia de Produção) - Universidade Federal de Santa Catarina, Florianópolis. 2004.

MERONI, A. Creative communities: people inventing sustainable ways of living. Milano: POLI. design, 2007.

MORAES, D. E. D. Metaprojeto: o design do design. São Paulo: Blucher, 2010.

MOZOTA, B. B. Gestão do design: usando o design para construir valor de marca e inovação corporativa. Porto Alegre: Bookman, 2011.

OS DESAFIOS da economia solidária. Disponível em: <http://economiasolidariasustentavel. blogspot.com.br/>. Acesso em: 1 abr. 2017.

OSTROWER, F. Criatividade e processos de criação. Petrópolis: Vozes, 1987.

PAPANEK, V. Design for the Real World: Human Ecology and Social Change. New York: Pantheon Books, 1971.

PETROSKI, H. A evolução das coisas úteis. Rio de Janeiro: Jorge Zahar, 1992.

PLAZA, J.; TAVARES, M. Processos criativos com os meios eletrônicos: poéticas digitais. São Paulo: Hucitec, 1998.

RITTEL, H. The reasoning of designers. Boston: Arbeitspapier zum International Congress on Planning and Design Theory, 1987.

SANTOS, M., PASCHOARELLI, L. Design e planejamento: aspectos técnicos. São Paulo: Cultura Acadêmica, 2009

SCHUMPETER, J. The creative response in economic history. The Journal of Economic History, Cambridge, 1947.

VEZZOLI, C. Design de sistemas para a sustentabilidade: teoria, métodos e ferramentas para o design sustentável de "sistemas de satisfação". Salvador: EdUFBA, 2010. 